

\title{
ChemComm
}

Check for updates

Cite this: Chem. Commun., 2020, 56, 10453

Received 10th July 2020 ,

Accepted 28th July 2020

DOI: $10.1039 / \mathrm{d} 0 \mathrm{cc} 04780 \mathrm{e}$

rsc.li/chemcomm

\section{Self-assembly of a porous metallo-[5]rotaxane $\dagger$}

\author{
Kevin Kei Gwan Wong, (D) Nadia Hoyas Pérez, Andrew J. P. White (D) and \\ James E. M. Lewis (DD *
}

A mechanically interlocked [2]rotaxane is reported incorporating a ditopic ligand moiety as one of the stoppers. Upon complexation with palladium(II) ions a metallo-[5]rotaxane was formed with a porous $\mathrm{Pd}_{2} \mathrm{~L}_{4}$ metal-organic cage at the core of the structure. This proof-of-principle system precedes work towards the construction of metal organic polyhedra with switchable mechano-chemical properties.

Metallo-supramolecular self-assembly has been a burgeoning topic over the last few decades, with the synthesis of metalorganic polyhedra (MOPs) of myriad geometries being achieved. ${ }^{1}$ With the ability to assemble discrete porous architectures in hand, MOPs have been examined for their applications in catalysis, ${ }^{2}$ drug delivery, ${ }^{3}$ and biomedicine, ${ }^{4}$ and used for stabilising reactive species, ${ }^{5}$ amongst others.

Generally, MOPs are highly symmetrical and ligand components are kept to a minimal level of complexity to avoid detrimental effects on the self-assembly process. However, more intricate assemblies may be desirable for specific applications. As such, in recent years, there has been an interest in developing methods for the construction of functionalised, ${ }^{6}$ heteroleptic, ${ }^{7}$ heteronuclear, ${ }^{8}$ and low symmetry structures. ${ }^{9}$ In addition there has been increasing activity towards incorporating dynamic $^{10}$ and stimuli-responsive components into MOPs. ${ }^{11}$ of particular note are recent examples by Clever and co-workers of assemblies, derived from photoswitchable dithienylethene-based ligands, capable of undergoing structural changes that modulate the host affinity for anionic guests. ${ }^{12}$

Mechanically interlocked molecules (MIMs) ${ }^{13}$ have emerged as a novel class of dynamic ligand. Borne out of interest in the ability of their components to undergo large amplitude relative

Department of Chemistry, Imperial College London, Molecular Sciences Research Hub, 80 Wood Lane, London W12 OBZ, UK. E-mail: james.lewis@imperial.ac.uk $\dagger$ Electronic supplementary information (ESI) available: Experimental details, spectroscopic data, NMR spectra, crystallographic details and computational methods. CCDC 2001103. For ESI and crystallographic data in CIF or other electronic format see DOI: $10.1039 /$ d0cc04780e motion, mechanically interlocked ligands ${ }^{14}$ have been used to assemble discrete complexes, ${ }^{15}$ as well as coordination oligomers ${ }^{16}$ and polymers. ${ }^{17}$ Indeed, Schurko, Loeb and coworkers have demonstrated both pirouetting ${ }^{18}$ and shuttling ${ }^{19}$ of macrocycles within metal-organic rotaxane frameworks (MORFs) $^{20}$ in the solid state, and Hupp, Farha, Stoddart and co-workers have reported the operation of an electrochemically switchable catenane residing in the pores of a MOF. ${ }^{21}$ Despite these exciting preliminary results, self-assembly with dynamic ligands is still a nascent area of research. ${ }^{22}$

The stimuli-responsive motion of MIMs has been exploited to control the ingress and egress of chemical payloads into and out of the pores of silica nanoparticles through changing the proximity of the steric bulk of an interlocked macrocycle relative to the pore opening. ${ }^{23}$ This concept could in theory be translated to MOPs, allowing occlusion of portals, thus inhibiting guest movement between the central cavity and external environment in a controlled manner. The modulation of steric bulk around the cage periphery could also offer the potential for allosteric regulation of catalysis. ${ }^{24}$

MOPs have been prepared with ligands that allow for the formation of dynamic libraries of metallo $[n]$ catenanes, ${ }^{25}$ and a mixed-metal cluster threaded with a ligand was recently shown to assemble into a capsular [13]rotaxane structure. ${ }^{26}$ However, to the best of our knowledge, there have been no reports on the use of organic MIMs as ligands for the self-assembly of metalorganic cages - three-dimensional, porous MOPs. In this work we report a proof-of-principle system in which a dipyridyl [2]rotaxane ligand is shown to self-assemble in the presence of palladium(II) ions to form a $\mathrm{Pd}_{2} \mathrm{~L}_{4}$ architecture in which the exohedral faces are decorated with four interlocked macrocycles; namely, a metallo-[5]rotaxane. These results validate principles of ongoing research towards the preparation of MOPs derived from interlocked ligands in which the proximity of sub-components can be manipulated in a stimuli-responsive manner, allowing control of payload exchange between the internal cage cavity and the external environment. 


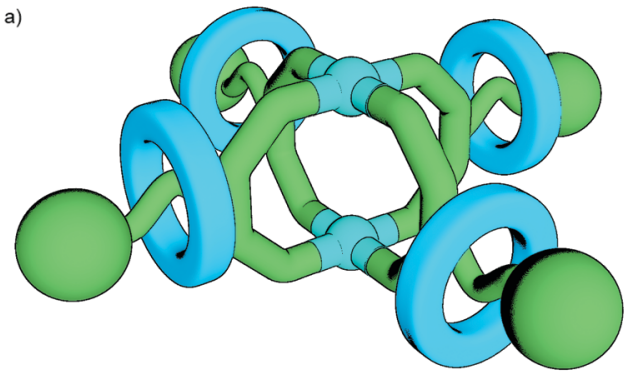

b)

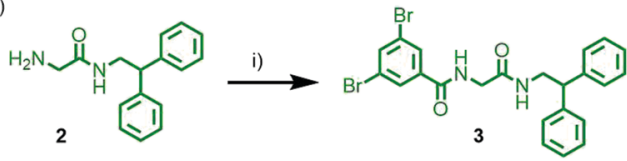

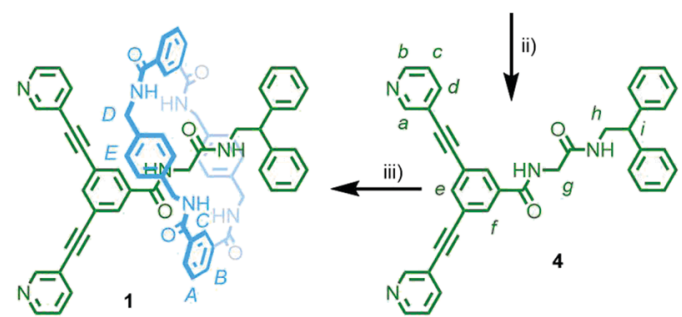

Scheme 1 (a) Cartoon representation of $\mathrm{Pd}_{2} \mathrm{~L}_{4}$ metallo-[5]rotaxane. (b) Synthesis of [2]rotaxane 1. Reagents and conditions: (i) 3,5-dibromobenzoic acid, EDC, DMAP, $\mathrm{CH}_{2} \mathrm{Cl}_{2}, \mathrm{rt}, 16 \mathrm{~h}, 77 \%$; (ii) 3-ethynylpyridine, $\left[\mathrm{Pd}\left(\mathrm{PPh}_{3}\right)_{2} \mathrm{Cl}_{2}\right.$ ], Cul, ${ }^{i} \mathrm{Pr}_{2} \mathrm{NH}, 80{ }^{\circ} \mathrm{C}, 16 \mathrm{~h}, 75 \%$; (iii) isophthaloyl chloride, $p$-xylylenediamine, $\mathrm{NEt}_{3}, \mathrm{CHCl}_{3}, \mathrm{rt}, 10 \%$.

[2]Rotaxane 1 (Scheme 1) was designed incorporating one diphenylmethane and one $m$-bis(pyridin-3-ylethynyl)phenyl stopper. The former simply acts as a physical barrier to prevent dethreading of the macrocycle, whilst the latter is a motif known to assemble in the presence of square planar palladium(II) ions to form quadruply-stranded dinuclear cage architectures, ${ }^{27}$ with cavities capable of binding guests through hydrogen bonding interactions. ${ }^{28}$ Provided the axle and macrocycle components do not interfere with the self-assembly of this ligand moiety, addition of palladium(II) ions to 1 would be expected to yield a metallo-[5]rotaxane with a porous core (Scheme 1a).

A straightforward synthetic route to $\mathbf{1}$ was identified (Scheme 1b). Precursor 2 was prepared from Boc-glycine and 2,2-diphenylethylamine according to literature procedure. ${ }^{29}$ Subsequent amide condensation with 3,5-dibromobenzoic acid (77\%), following by Sonogashira coupling with 3-ethynylpyridine (75\%), gave non-interlocked axle 4 in 58\% yield over the two steps (see ESI $\dagger$ for details).

It was deemed prudent to examine binding of palladium(II) ions with the axle component by itself initially. To this end, 4 was combined with 0.5 equivalents of $\left[\mathrm{Pd}\left(\mathrm{CH}_{3} \mathrm{CN}\right)_{4}\right]\left(\mathrm{BF}_{4}\right)_{2}$ in $d_{6}$ DMSO. Immediate ( $<10$ minutes) formation of a new species was observed by ${ }^{1} \mathrm{H}$ NMR spectroscopy (Fig. 1b), with significant downfield shifts of the protons adjacent to the pyridyl nitrogen atoms $\left(\mathrm{H}_{a}\right.$ and $\mathrm{H}_{b}, \Delta \delta=0.80$ and $0.77 \mathrm{ppm}$, respectively) indicating coordination of the palladium(II) ions. From DOSY NMR (Fig. 1c and Table 1) the diffusion coefficient, $D$, of the complex $\left(7.76 \times 10^{-11} \mathrm{~m}^{2} \mathrm{~s}^{-1}\right)$ was found to be approximately half that of

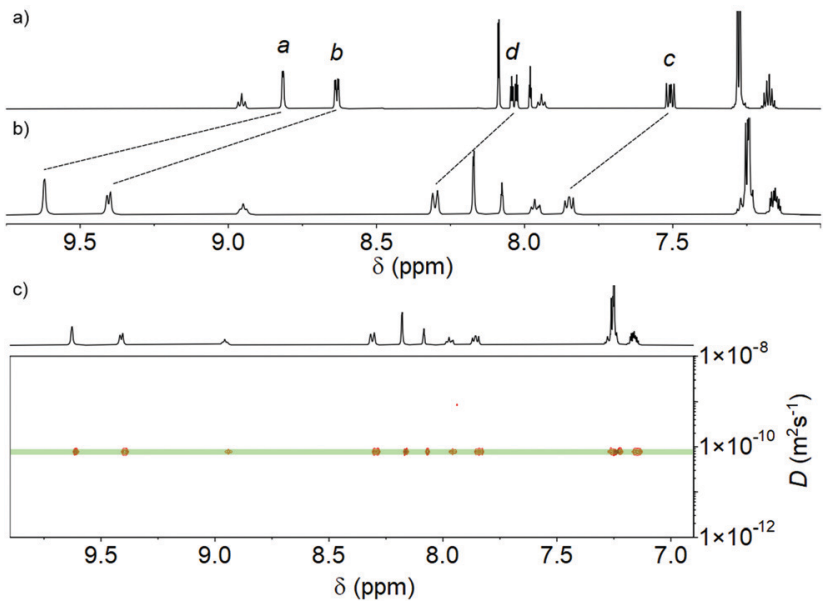

Fig. $1{ }^{1} \mathrm{H}$ NMR spectra (500 MHz, $d_{6}$-DMSO, $298 \mathrm{~K}$ ) of (a) 4, and (b) $\left[\mathrm{Pd}_{2}(\mathbf{4})_{4}\right]\left(\mathrm{BF}_{4}\right)_{4}$, and (c) DOSY NMR spectrum $\left(500 \mathrm{MHz}, d_{6}-\mathrm{DMSO}, 298 \mathrm{~K}\right)$ of $\left[\mathrm{Pd}_{2}(4)_{4}\right]\left(\mathrm{BF}_{4}\right)_{4}$. For axle labelling see Scheme 1.

the ligand $\left(1.72 \times 10^{-10} \mathrm{~m}^{2} \mathrm{~s}^{-1}\right)$, congruous with previous reports of $\mathrm{Pd}_{2} \mathrm{~L}_{4}$ cages, and gave a calculated hydrodynamic radius $\left(R_{\mathrm{H}}\right)$ consistent with the optimised structure of the $\mathrm{Pd}_{2} \mathrm{~L}_{4}$ 'paddlewheel' assembly (13.0 A; see ESI $\dagger$ ). Finally, isotopic patterns consistent with this architecture were observed by mass spectrometry (MS; Fig. S25-S27, ESI $\dagger$ ). ${ }^{30}$

Having confirmed that the axle did not interfere with the selfassembly of the ligand stopper unit, [2]rotaxane 1 was subsequently prepared. The rotaxane ligand was synthesised under pseudo-high dilution conditions through simultaneous addition of solutions of isophthaloyl dichloride and $p$-xylylenediamine to a solution of the axle, 4 , and $\mathrm{NEt}_{3}$ in anhydrous $\mathrm{CHCl}_{3}$, resulting in clipping of the tetralactam macrocycle around the glycylglycine motif, ${ }^{31}$ giving 1 in $10 \%$ isolated yield (the low yield is chiefly ascribed to the proximity of the bulky dipyridine stopper to the template motif).

The identity and interlocked nature of the ligand was confirmed by MS $\left(m / z=1115[\mathrm{M}+\mathrm{Na}]^{+}\right)$and NMR spectroscopy (Fig. 2b). In comparison to the free axle (Fig. 2a) most signals of the dipyridyl stopper were minimally perturbed ( $\Delta \delta \leq 0.1 \mathrm{ppm})$. However, $\mathrm{H}_{f}$, directed towards the glycylglycine unit, was shifted dramatically upfield ( $\Delta \delta=0.38 \mathrm{ppm})$, as was $\mathrm{H}_{g}$, the methylene unit upon which the macrocycle was expected to reside $(\Delta \delta=1.39)$. Additionally, signals for both the axle and macrocycle components were observed to diffuse at the same rate by DOSY NMR (Fig. S17, ESI $\dagger$ ).

Ultimately the mechanically interlocked structure of $\mathbf{1}$ was confirmed in the solid state by single crystal X-ray diffraction

Table 1 Diffusion coefficients determined by ${ }^{1} \mathrm{H}$ DOSY NMR spectroscopy $\left(500 \mathrm{MHz}, d_{6}\right.$-DMSO, $298 \mathrm{~K}$ ) and calculated $R_{\mathrm{H}}$ values

\begin{tabular}{llrl}
\hline Compound & $D\left(\mathrm{~m}^{2} \mathrm{~s}^{-1}\right)$ & $R_{\mathrm{H}}(\AA)$ & $D$ ligand/cage ratio \\
\hline $\mathbf{4}$ & $1.72 \times 10^{-10}$ & 5.9 & 2.2 \\
{$\left[\mathrm{Pd}_{2}(\mathbf{4})_{4}\right]\left(\mathrm{BF}_{4}\right)_{4}$} & $7.76 \times 10^{-11}$ & 13.0 & \\
$\mathbf{1}$ & $1.26 \times 10^{-10}$ & 8.0 & 1.9 \\
{$\left[\mathrm{Pd}_{2}(\mathbf{1})_{4}\right]\left(\mathrm{BF}_{4}\right)_{4}$} & $6.81 \times 10^{-11}$ & 14.8 &
\end{tabular}



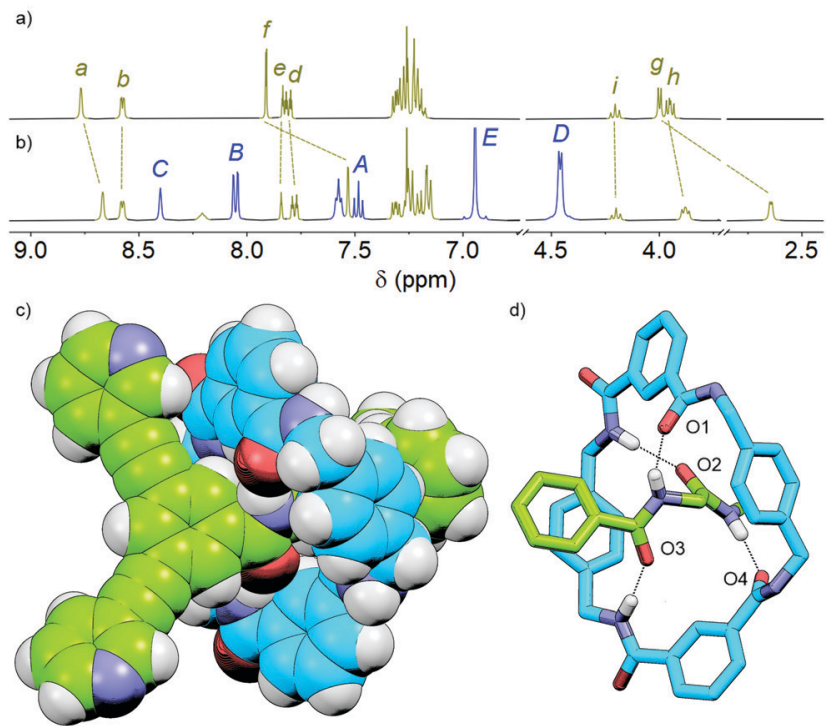

Fig. $2{ }^{1} \mathrm{H}$ NMR spectra (400 MHz, $\mathrm{CDCl}_{3}, 298 \mathrm{~K}$ ) of (a) axle 4, and (b) [2]rotaxane 1. For axle and macrocycle labelling see Scheme 1. (c) SCXRD structure of 1 shown as space-fill model, and (d) abbreviated structure showing intercomponent $\mathrm{H}$-bonding interactions (hydrogen atoms not involved in intramolecular $\mathrm{H}$-bonding omitted for clarity). Distances ( $\AA$ )

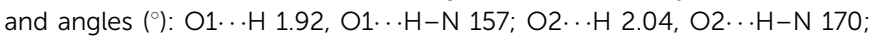

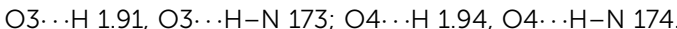

(SCXRD; Fig. 2c). The SCXRD structure of 1 showed two of the macrocyclic carbonyl groups to be directed endohedrally, the other two exohedrally, to give four intramolecular, intercomponent $\mathrm{N}-\mathrm{H} \cdots$ carbonyl hydrogen bonding interactions between

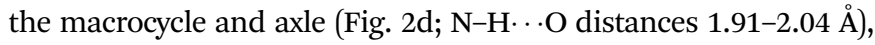
a motif previously observed in the solid state structures of similar systems. ${ }^{29,32}$

With the rotaxane in hand the self-assembly of the interlocked ligand with palladium(II) was examined. Pleasingly, addition of $\left[\mathrm{Pd}\left(\mathrm{CH}_{3} \mathrm{CN}\right)_{4}\right]\left(\mathrm{BF}_{4}\right)_{2}$ to rotaxane 1 in $d_{6}$-DMSO resulted in similar behaviour to the non-interlocked axle. A single set of signals was observed in the ${ }^{1} \mathrm{H}$ NMR spectrum (Fig. 3b), with downfield shifts $\left(\Delta \delta=0.78\right.$ and $0.73 \mathrm{ppm}$ for $\mathrm{H}_{a}$ and $\mathrm{H}_{b}$, respectively) of the pyridyl signals relative to the free ligand (Fig. 3a), indicating coordination to the palladium(II) ions. A diffusion coefficient of $6.81 \times 10^{-11} \mathrm{~m}^{2} \mathrm{~s}^{-1}$ (Fig. 3c and Table 1) was observed by DOSY NMR, approximately half that of the ligand $\left(1.26 \times 10^{-10} \mathrm{~m}^{2} \mathrm{~s}^{-1}\right)$, corresponding to an $R_{\mathrm{H}}$ of $14.8 \AA$ A consistent with the optimised structure of the assembly (Fig. 3d and e). With further support from MS $(\mathrm{m} / \mathrm{z}=1542$ $\left.\left\{\left[\operatorname{Pd}_{2}(\mathbf{1})_{4}\right]\left(\mathrm{A}^{-}\right)\right\}^{3+}\right),{ }^{30}$ the successful formation of the desired $\mathrm{Pd}_{2} \mathrm{~L}_{4}$, metallo-[5]rotaxane was concluded. Although the use of DMSO as solvent precluded the use of variable temperature NMR experiments to determine a rate constant, the observation of a single set of signals for the macrocycle component (Fig. 3b) indicated that in the metallo-[5]rotaxane structure these remain sufficiently unencumbered to continue pirouetting about the axles at a fast rate compared to the NMR timescale.

In summary we have reported the synthesis of a [2] rotaxane ligand capable of self-assembly with palladium(II) ions to form
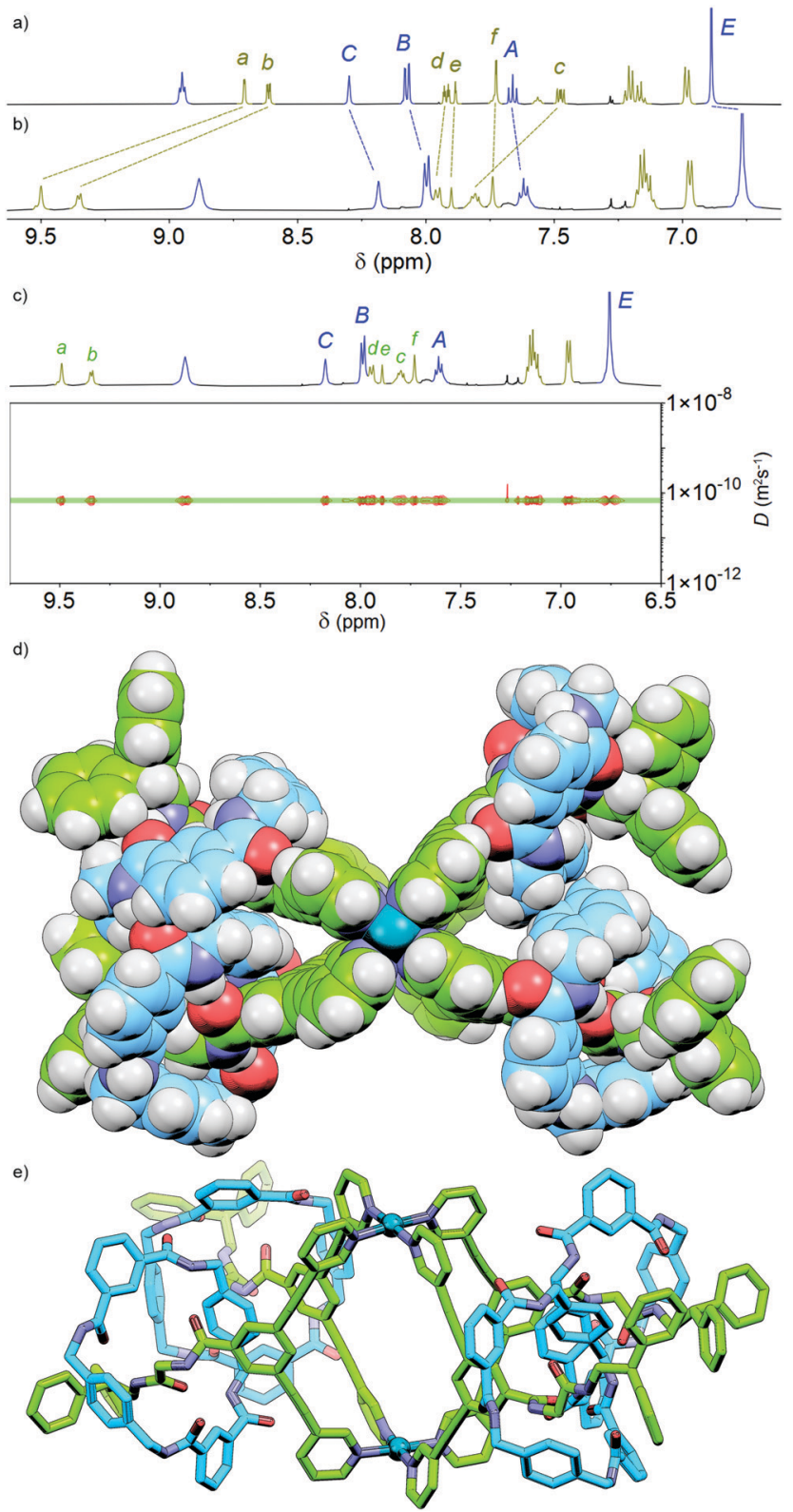

Fig. $3{ }^{1} \mathrm{H}$ NMR spectra (500 MHz, $d_{6}$-DMSO, $298 \mathrm{~K}$ ) of (a) [2]rotaxane 1 , and (b) metallo-[5]rotaxane $\left[\mathrm{Pd}_{2}(\mathbf{1})_{4}\right]\left(\mathrm{BF}_{4}\right)_{4}$. (c) DOSY NMR spectrum $\left(500 \mathrm{MHz}, d_{6}\right.$-DMSO, $298 \mathrm{~K}$ ) of $\left[\mathrm{Pd}_{2}(\mathbf{1})_{4}\right]\left(\mathrm{BF}_{4}\right)_{4}$. For axle and macrocycle labelling see Scheme 1. Geometry optimised structure (PM6) of $\left[\mathrm{Pd}_{2}(\mathbf{1})_{4}\right]^{4+}$ shown (d) down the Pd-Pd axis, and (e) from the side.

a porous metallo-supramolecular cage with exohedral rotaxane units, i.e. a metallo-[5]rotaxane. This proof-of-principle system highlights the potential for incorporating dynamic mechanically interlocked components into MOPs. In this current model system the macrocycle components are dynamic in terms of rotational motion (pirouetting), but static with respect to linear motion, i.e. shuttling, along the axle. Work in our lab is now ongoing to prepare ligands incorporating stimuli-responsive mechanically interlocked moieties into the framework, offering the potential for triggered occlusion of cage portals. In this manner it is hoped the kinetics of guest exchange with the host cavity may be modulated in a controllable manner. ${ }^{33}$ 
This work was supported by an Imperial College Research Fellowship (JEML) and a Royal Society Research Grant (RG170321). We thank Peter Haycock for assistance with NMR data collection, Dr Lisa Haigh for MS, and Prof. Matthew Fuchter for useful discussions and access to resources.

\section{Conflicts of interest}

There are no conflicts to declare.

\section{Notes and references}

1 (a) M. Fujita, Chem. Soc. Rev., 1998, 27, 417-425; (b) S. Leininger, B. Olenyuk and P. J. Stang, Chem. Rev., 2000, 100, 853-907; (c) B. J. Holliday and C. A. Mirkin, Angew. Chem., Int. Ed., 2001, 40, 2022-2043; (d) R. Chakrabarty, P. S. Mukherjee and P. J. Stang, Chem. Rev., 2011, 111, 6810-6918; (e) T. R. Cook and P. J. Stang, Chem. Rev., 2015, 115, 7001-7045.

2 (a) M. Yoshizawa, J. K. Klosterman and M. Fujita, Angew. Chem., Int. Ed., 2009, 48, 3418-3438; (b) L. J. Jongkind, X. Caumes, A. P. T. Hartendorp and J. N. H. Reek, Acc. Chem. Res., 2018, 51, 2115-2128; (c) I. Sinha and P. S. Mukherjee, Inorg. Chem., 2018, 57, 4205-4221; (d) C. Tan, D. Chu, X. Tang, Y. Liu, W. Xuan and Y. Cui, Chem. - Eur. J., 2019, 25, 662-672; (e) Y. Fang, J. A. Powell, E. Li, Q. Wang, Z. Perry, A. Kirchon, X. Yang, Z. Xiao, C. Zhu, L. Zhang, F. Huang and H. C. Zhou, Chem. Soc. Rev., 2019, 48, 4707-4730; $(f)$ R. J. Severinsen, G. J. Rowlands and P. G. Plieger, J. Inclusion Phenom. Macrocyclic Chem., 2020, 96, 29-42.

3 (a) B. Therrien, G. Süss-Fink, P. Govindaswamy, A. K. Renfrew and P. J. Dyson, Angew. Chem., Int. Ed., 2008, 47, 3773-3776; (b) J. E. M. Lewis, E. L. Gavey, S. A. Cameron and J. D. Crowley, Chem. Sci., 2012, 3, 778-784.

4 (a) T. R. Cook, V. Vajpayee, M. H. Lee, P. J. Stang and K. W. Chi, Acc. Chem. Res., 2013, 46, 2464-2474; (b) A. Casini, B. Woods and M. Wenzel, Inorg. Chem., 2017, 56, 14715-14729; (c) H. Sepehrpour, W. Fu, Y. Sun and P. J. Stang, J. Am. Chem. Soc., 2019, 141, 14005-14020.

5 (a) P. Mal, B. Breiner, K. Rissanen and J. R. Nitschke, Science, 2009, 324, 1697-1699; (b) M. Yamashina, Y. Sei, M. Akita and M. Yoshizawa, Nat. Commun., 2014, 5, 4662; (c) K. Niki, T. Tsutsui, M. Yamashina, M. Akita and M. Yoshizawa, Angew. Chem., Int. Ed., 2020, 59, 10489-10492.

6 (a) M. Tominaga, K. Suzuki, T. Murase and M. Fujita, J. Am. Chem. Soc., 2005, 127, 11950-11951; (b) N. Kamiya, M. Tominaga, S. Sato and M. Fujita, J. Am. Chem. Soc., 2007, 129, 3816-3817; (c) J. E. M. Lewis, C. J. McAdam, M. G. Gardiner and J. D. Crowley, Chem. Commun., 2013, 49, 3398-3400; (d) J. E. M. Lewis, A. B. S. Elliott, C. J. McAdam, K. C. Gordon and J. D. Crowley, Chem. Sci., 2014, 5, 1833-1843.

7 (a) W. M. Bloch and G. H. Clever, Chem. Commun., 2017, 53, 8506-8516; (b) D. Bardhan and D. K. Chand, Chem. - Eur. J., 2019, 25, 12241-12269.

8 (a) L. Li, D. J. Fanna, N. D. Shepherd, L. F. Lindoy and F. Li, J. Inclusion Phenom. Macrocyclic Chem., 2015, 82, 3-12; (b) H. Li, Z. J. Yao, D. Liu and G. X. Jin, Coord. Chem. Rev., 2015, 293-294, 139-157; (c) M. Hardy and A. Lützen, Chem. - Eur. J., 2020, DOI: 10.1002/chem.202001602.

9 (a) J. E. M. Lewis and J. D. Crowley, ChemPlusChem, 2020, 85, 815-827; (b) S. Hiraoka and M. Fujita, J. Am. Chem. Soc., 1999, 121, 10239-10240; (c) S. K. Sen and R. Natarajan, Inorg. Chem., 2019, 58, 7180-7188; (d) D. Ogata and J. Yuasa, Angew. Chem., Int. Ed., 2019, 58, 18424-18428; (e) J. E. M. Lewis, A. Tarzia, A. J. P. White and K. E. Jelfs, Chem. Sci., 2020, 11, 677-683; $(f)$ L. S. Lisboa, J. A. Findlay, L. J. Wright, C. G. Hartinger and J. D. Crowley, Angew. Chem., Int. Ed., 2020, 59, 11101-11107.
10 (a) M. Krick, J. Holstein, C. Würtele and G. H. Clever, Chem. Commun., 2016, 52, 10411-10414; (b) S. Löffler, J. Lübben, A. Wuttke, R. A. Mata, M. John, B. Dittrich and G. H. Clever, Chem. Sci., 2016, 7, 4676-4684.

11 (a) M. Han, Y. Luo, B. Damaschke, L. Gómez, X. Ribas, A. Jose, P. Peretzki, M. Seibt and G. H. Clever, Angew. Chem., Int. Ed., 2016, 55, 445-449; (b) S. Oldknow, D. R. Martir, V. E. Pritchard, M. A. Blitz, C. W. G. Fishwick, E. Zysman-Colman and M. J. Hardie, Chem. Sci., 2018, 9, 8150-8159; (c) Y. Gu, E. A. Alt, H. Wang, X. Li, A. P. Willard and J. A. Johnson, Nature, 2018, 560, 65-69.

12 (a) M. Han, R. Michel, B. He, Y. S. Chen, D. Stalke, M. John and G. H. Clever, Angew. Chem., Int. Ed., 2013, 52, 1319-1323; (b) R. J. Li, J. J. Holstein, W. G. Hiller, J. Andréasson and G. H. Clever, J. Am. Chem. Soc., 2019, 141, 2097-2103.

13 C. J. Bruns and J. F. Stoddart, The Nature of the Mechanical Bond, John Wiley \& Sons, Inc., Hoboken, NJ, USA, 2016.

14 J. E. M. Lewis, M. Galli and S. M. Goldup, Chem. Commun., 2017, 53, 298-312.

15 (a) G. J. E. Davidson and S. J. Loeb, Dalton Trans., 2003, 3, 4319-4323; (b) A. Noor, W. K. C. Lo, S. C. Moratti and J. D. Crowley, Chem. Commun., 2014, 50, 7044-7047; (c) E. Viljoen, K. Zhu and S. J. Loeb, Chem. - Eur. J., 2016, 22, 7479-7484.

16 (a) C. Hamers, O. Kocian, F. M. Raymo and J. F. Stoddart, Adv. Mater., 1998, 10, 1366-1369; (b) A. Noor, S. C. Moratti and J. D. Crowley, Chem. Sci., 2014, 5, 4283-4290.

17 (a) V. N. Vukotic and S. J. Loeb, Chem. Soc. Rev., 2012, 41, 5896-5906; (b) L. Gao, Z. Zhang, B. Zheng and F. Huang, Polym. Chem., 2014, 5, 5734-5739; (c) Y. Shi, Z. Yang, H. Liu, Z. Li, Y. Tian and F. Wang, ACS Macro Lett., 2015, 4, 6-10; (d) J. E. M. Lewis, Org. Biomol. Chem., 2019, 17, 2442-2447.

18 V. N. Vukotic, K. J. Harris, K. Zhu, R. W. Schurko and S. J. Loeb, Nat. Chem., 2012, 4, 456-460.

19 K. Zhu, C. A. O'Keefe, V. N. Vukotic, R. W. Schurko and S. J. Loeb, Nat. Chem., 2015, 7, 514-519.

20 S. J. Loeb, Chem. Commun., 2005, 1511-1518.

21 Q. Chen, J. Sun, P. Li, I. Hod, P. Z. Moghadam, Z. S. Kean, R. Q. Snurr, J. T. Hupp, O. K. Farha and J. F. Stoddart, J. Am. Chem. Soc., 2016, 138, 14242-14245.

22 H. Deng, M. A. Olsen, J. F. Stoddart and O. M. Yaghi, Nat. Chem., 2010, 2, 439-443.

23 M. W. Ambrogio, C. R. Thomas, Y. L. Zhao, J. I. Zink and J. F. Stoddart, Acc. Chem. Res., 2011, 44, 903-913.

24 V. Martí-Centelles, R. L. Spicer and P. J. Lusby, Chem. Sci., 2020, 11, 3236-3240.

25 (a) S. P. Black, A. R. Stefankiewicz, M. M. J. Smulders, D. Sattler, C. A. Schalley, J. R. Nitschke and J. K. M. Sanders, Angew. Chem., Int. Ed., 2013, 52, 5749-5752; (b) S. P. Black, D. M. Wood, F. B. Schwarz, T. K. Ronson, J. J. Holstein, A. R. Stefankiewicz, C. A. Schalley, J. K. M. Sanders and J. R. Nitschke, Chem. Sci., 2016, 7, 2614-2620.

26 J. Ferrando-Soria, A. Fernandez, D. Asthana, S. Nawaz, I. J. VitoricaYrezabal, G. F. S. Whitehead, C. A. Muryn, F. Tuna, G. A. Timco, N. D. Burton and R. E. P. Winpenny, Nat. Commun., 2019, 10, 3720.

27 P. Liao, B. W. Langloss, A. M. Johnson, E. R. Knudsen, F. S. Tham, R. R. Julian and R. J. Hooley, Chem. Commun., 2010, 46, 4932-4934.

28 D. P. August, G. S. Nichol and P. J. Lusby, Angew. Chem., Int. Ed., 2016, 55, 15022-15026.

29 D. S. Marlin, D. G. Cabrera, D. A. Leigh and A. M. Z. Slawin, Angew. Chem., Int. Ed., 2006, 45, 77-83.

30 Despite preparing the $\mathrm{BF}_{4}^{-}$salts of the cages, under the MS conditions the dominant peaks corresponded to $\mathrm{HCO}_{2}{ }^{-}$adducts. However, the isotopic patterns observed were consistent with the cationic $\operatorname{Pd}_{2} \mathrm{~L}_{4}$ assemblies.

31 D. A. Leigh, A. Murphy, J. P. Smart and A. M. Z. Slawin, Angew. Chem., Int. Ed. Engl., 1997, 36, 728-732.

32 D. M. D'Souza, D. A. Leigh, L. Mottier, K. M. Mullen, F. Paolucci, S. J. Teat and S. Zhang, J. Am. Chem. Soc., 2010, 132, 9465-9470.

33 T. Y. Kim, R. A. S. Vasdev, D. Preston and J. D. Crowley, Chem. - Eur. J., 2018, 24, 14878-14890. 